\title{
A new species of parasitic wasp Neastymachus Girault (Hymenoptera: Chalcidoidea: Encyrtidae) collected by fogging Vateria indica L. (Dipterocarpaceae) canopy in the Western Ghats of India
}

\author{
Sudhir Singh ${ }^{1} \&$ Y.B. Srinivasa ${ }^{2}$ \\ ${ }^{1}$ Forest Entomology Division, Forest Research Institute, New Forest, Dehra Dun, Uttarakhand 248006, India \\ ${ }^{2}$ Institute of Wood Science and Technology, P.O. Malleswaram, Bangaluru, Karnataka 560003, India \\ Email: ${ }^{1}$ sudhirs@icfre.org (corresponding author), ${ }^{2}$ ybsrinivasa@gmail.com
}

\begin{abstract}
A new species of the encyrtid genus Neastymachus (N. punctatiscutellum Singh, sp. nov.) is described from a female specimen collected from the Western Ghats of India. It was collected by fogging the canopy of Vateria indica L. (Dipterocarpaceae). A key to the females of the Afrotropical, Australian and Oriental species is also given.
\end{abstract}

Keywords: Canopy fogging, Discodini, Encyrtidae, Hymenoptera, new species.

Rainforest canopies are a treasure trove of biodiversity, adaptations and complex interactions (Mitchell 1986). Forest arthropods contribute majority of this species diversity which in turn is due to large number of insects in the canopy (Erwin 1982, 1983). Tropical rainforest insects are more abundant in the

Date of publication (online): 26 August 2012

Date of publication (print): 26 August 2012

ISSN $0974-7907$ (online) | 0974-7893 (print)

Editor: Md. Hayat

\section{Manuscript details:}

Ms \# 02960

Received 30 September 2011

Final received 13 June 2012

Finally accepted 18 July 2012

Citation: Sudhir Singh \& Y.B. Srinivasa (2012). A new species of parasitic wasp Neastymachus Girault (Hymenoptera: Chalcidoidea: Encyrtidae) collected by fogging Vateria indica L. (Dipterocarpaceae) canopy in the Western Ghats of India. Journal of Threatened Taxa 4(9): 2883-2888.

Copyright: () Sudhir Singh \& Y.B. Srinivasa 2012. Creative Commons Attribution 3.0 Unported License. JoTT allows unrestricted use of this article in any medium for non-profit purposes, reproduction and distribution by providing adequate credit to the authors and the source of publication.

Acknowledgements: The first author is thankful to Dr. S.S. Negi, the Director, Forest Research Institute, and Dr. Mohd. Yousuf, the Head, Forest Entomology Division for providing the necessary laboratory facilities. We are also thankful to Indian Council of Forestry Research and Education for funding the research work. First author is thankful to Dr. Mohd. Hayat, Department of Zoology, AMU, Aligarh for his comments and verifying the material during his visit to $\mathrm{FRI}$, Dehradun. Thanks are also due to the two unknown reviewers for their valuable comments and suggestions for improving the quality of the paper.

\section{OPEN ACCESS | FREE DOWNLOAD}

canopy than near the forest floor (Erwin 1982; Smythe 1982; Erwin 1983; Sutton et al. 1983; Stork 1991). A number of insect diversity works have been done in the rainforests of South America and elsewhere in the world, but in India studies on canopy biodiversity are negligible. Srinivasa et al. (2004) has done some work on insect diversity in the canopies of two rainforest species Vateria indica L. and Dipterocarpus indicus Bedd. (Dipterocarpaceae) from linear tree increment plot that lay undisturbed since the 1920s. From this collection chalcids were also recovered, some of which were found new to science. Singh, in Singh \& Srinivasa (2010) has already described a new species of Eutrichosomella Girault (Hymenoptera: Aphelinidae) collected during this study. In the present work a new species of the genus Neastymachus Girault (1915) (Hymenoptera: Chalcidoidea: Encyrtidae) is described. A key to some species of this genus is also given.

\section{Material and Methods}

This species was collected from canopies of Vateria indica L. trees located at an altitude of $128 \mathrm{~m}$, which had a moderately dense canopy and about $40 \mathrm{~m}$ tall with the lower most branch at about $22 \mathrm{~m}$ from the ground. At the time of sampling, $V$. indica was fruiting. Samples were obtained using an insecticide fog (Kingfog ${ }^{\circledR} @$ of $0.34 \%$ a.i.) generated from a thermal fogger (Vanfog ${ }^{\circledR}$ ) (Srinivasa et al. 2004).

Body length is given in millimeters. All other measurements are in $\mu \mathrm{m}$. The holotype of the new species is deposited in the National Forest Insect Collection, Entomology Division of the Forest Research Institute, Dehradun, India (NFIC-FRI).

Abbreviations and measurements used in the text are according to Noyes \& Hayat (1984) and Singh \& Agarwal (1993). 


\section{Genus Neastymachus Girault}

Neastymachus Girault, 1915:86. Type species Neastymachus auraticorpus Girault, by monotypy.

Nikolskiella Trjapitzin and Pseudmicroterys Shafee, Alam \& Agarwal are synonyms of the genus (Noyes \& Hayat 1984).

Diagnosis: Head in frontal view wider than high; antennal scrobes shallow or moderately impressed with lateral margins rounded, not longer than half the distance between a torulus and median ocellus. Funicle 6-segmented; club 3-segmented, apex rounded. Mandibles tridentate or with two sharp teeth and a truncation. Wing hyaline, marginal vein at least two times as long as wide. Hypopygium not extending more than two-thirds length along gaster; ovipositor either not exserted or only slightly exserted. Body generally yellow, orange or brownish-yellow to dark brown; gaster darker than rest of the body. Antenna yellowish, with scape and club may be brown. Legs completely pale yellow.

Comments: The type species of Neastymachus and the Palaearctic and Costa Rican species have short notaular lines (=parapsidal furrows) on the mesoscutum (Dahms \& Gordh 1997; Noyes 2010). The Indian species lack notaular lines on the mesoscutum. But a short curved darker line is present on either side of mesoscutum just behind the pronotum which is a narrow gap in the underlying muscles visible through translucent mesoscutum. However, reflections from sculptural patterns from this area show no sign of any groove or ridge. Similar pattern was also seen in the holotypes of $N$. axillaris and $N$. latiscapus. On the basis of setation on base of the fore wing, shape of gaster and location of the cercal plates and colour pattern of the pronotum, Hayat (1999) divided Indian species into two groups: the cerococci group with four species (angustifrons, burksi, cerococci and latiscapus) and the delhiensis group with two species (axillaris and delhiensis). Hayat did not elaborate on the colour of pronotum. It has been observed that all the species from India and Australia have a black spot or band on anterior face of pronotum and a corresponding dark band or spots on the occiput (same may be present on the African species but due to its darker colour these characters may not be distinguishable. All the species in cerococci group usually have a dark brown spot on the pronotum, whereas delhiensis group has a narrow dark brown band on the pronotum and also brown spots or band on the occiput of head behind eyes.

The genus belongs to tribe Discodini (Hayat 2006; Noyes 2010). They are parasitoids of families Aclerdidae and Asterolecaniidae of Hemiptera (Noyes \& Hayat 1984).

\section{Species and distribution}

Neastymachus is an old world genus with 14 described species (including the new one). The genus is represented by two undescribed species in the Nearctic region (Noyes et al. 1997). The region wise distribution of species is as follows:

Afrotropical (1): Neastymachus dispar Prinsloo, 1996.

Australian (1): Neastymachus auraticorpus Girault, 1915.

Oriental (7, all from India): Neastymachus angustifrons (Shafee, Alam \& Agarwal, 1975); N. axillaris Singh, Agarwal \& Basha, 1991; N. burksi (Shafee, Alam \& Agarwal, 1975); N. cerococci (Shafee, Alam \& Agarwal, 1975); N. delhiensis (Subba Rao, 1957); N. latiscapus Singh, Agarwal \& Basha, 1991 and $N$. punctatiscutellum Singh, sp. nov.

Palaearctic (3): N. luteus (Nikol'skaya, 1952), $N$. secundus (Trjapitzin, 1962) and $N$. japonicus (Tachikawa, 1970).

Neotropical (2, from Costa Rica): $N$. orthanes Noyes, 2010; N. peyries Noyes, 2010.

\section{Neastymachus punctatiscutellum Singh, sp. nov. (Images 1-10)}

Material examined: Holotype: 26.vi.2003, female (on card, with both antennae, wings, fore and middle legs and left hind leg mounted on a slide under five cover slips), $\left(12^{\circ} 04^{\prime} 39.2^{\prime \prime} \mathrm{N} \& 75^{\circ} 43^{\prime} 33.6^{\prime \prime} \mathrm{E}\right)$ in the Western Ghats; ex. canopies of Vateria indica, located at an altitude of $128 \mathrm{~m}$; collected by canopy fogging, Makuta near Virajpet, Bannadapaare, Karnataka, India, coll. Y.B. Srinivasa. (NFIC-FRI, Dehradun. Accession No. 21906).

Diagnosis: Female: Body pale yellow except scutellum and middle portion of scape brownish. Scutellum asetose, with distinct punctate reticulate sculpture and with conical distal margin, basal portion of fore wing naked.

Description: Female, length $1.65 \mathrm{~mm}$ (holotype). Colour, setation and sculpture: Body completely 

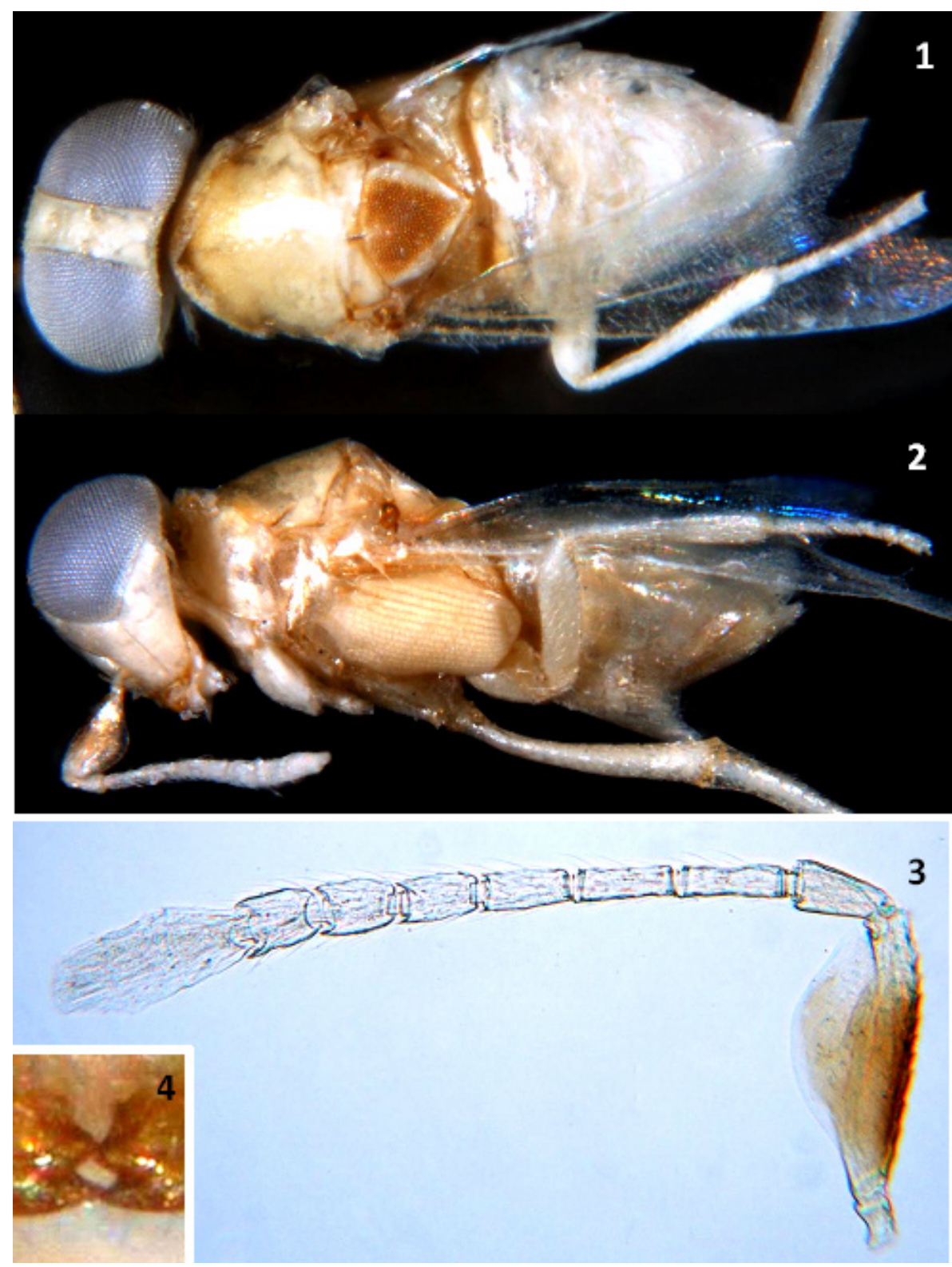

Images 1-4. Neastymachus punctatiscutellum Singh, sp. nov., female (holotype)

1 - body in dorsal view; 2 - body in lateral view; 3 - antenna; 4 - dentitions of mandibles. (c) Sudhir Singh

pale yellow except central part of scutellum and middle portion of scape brownish. Head completely pale yellow with very faint and shallow reticulate sculpture, sculpture much distinct at ocellar region than around scrobes; setae translucent and very inconspicuous, along the inner margins of eye setae longer; eyes naked, light grey in colour, ocelli colourless; mandible with teeth reddish-brown; maxillary and labial palpi pale yellow. Antenna white, except scape with basal two-thirds of brown, ventral margin and apical third white; pedicel slightly pale yellow; funicle segments with translucent, fine and long setae. Mesosoma pale yellow except central area of scutellum brownish; collar of pronotum with about 20 moderately strong setae; mesoscutum pale yellow with faint and very shallow reticulate sculpture which is larger than that on head, with about 100 pale, inconspicuous and scattered setae; axillae pale yellow and smooth, with one or two setae; scutellum brown, except narrow pale yellow stripes on sides; brown area of scutellum with prominent punctate reticulate sculpture (Image 8), setae absent; lateral pale stripes of scutellum smooth. Wings hyaline, venation almost translucent; setae transparent and hardly visible even under higher magnification of compound microscope; basal portion of fore wing naked. All legs pale yellow, lighter than mesosoma. Metasoma pale yellow, lighter than mesosoma, with inconspicuous setae. 

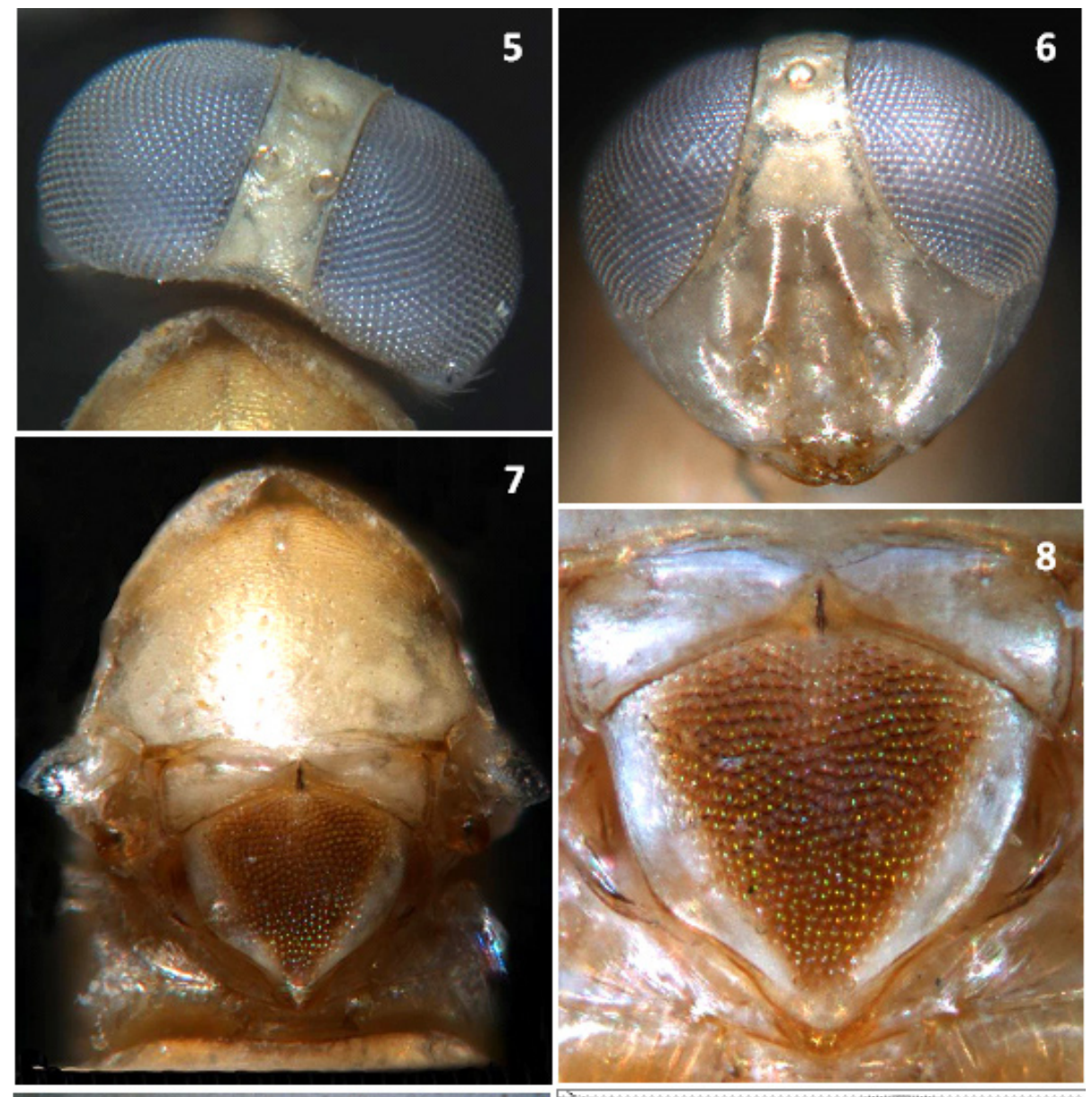

6
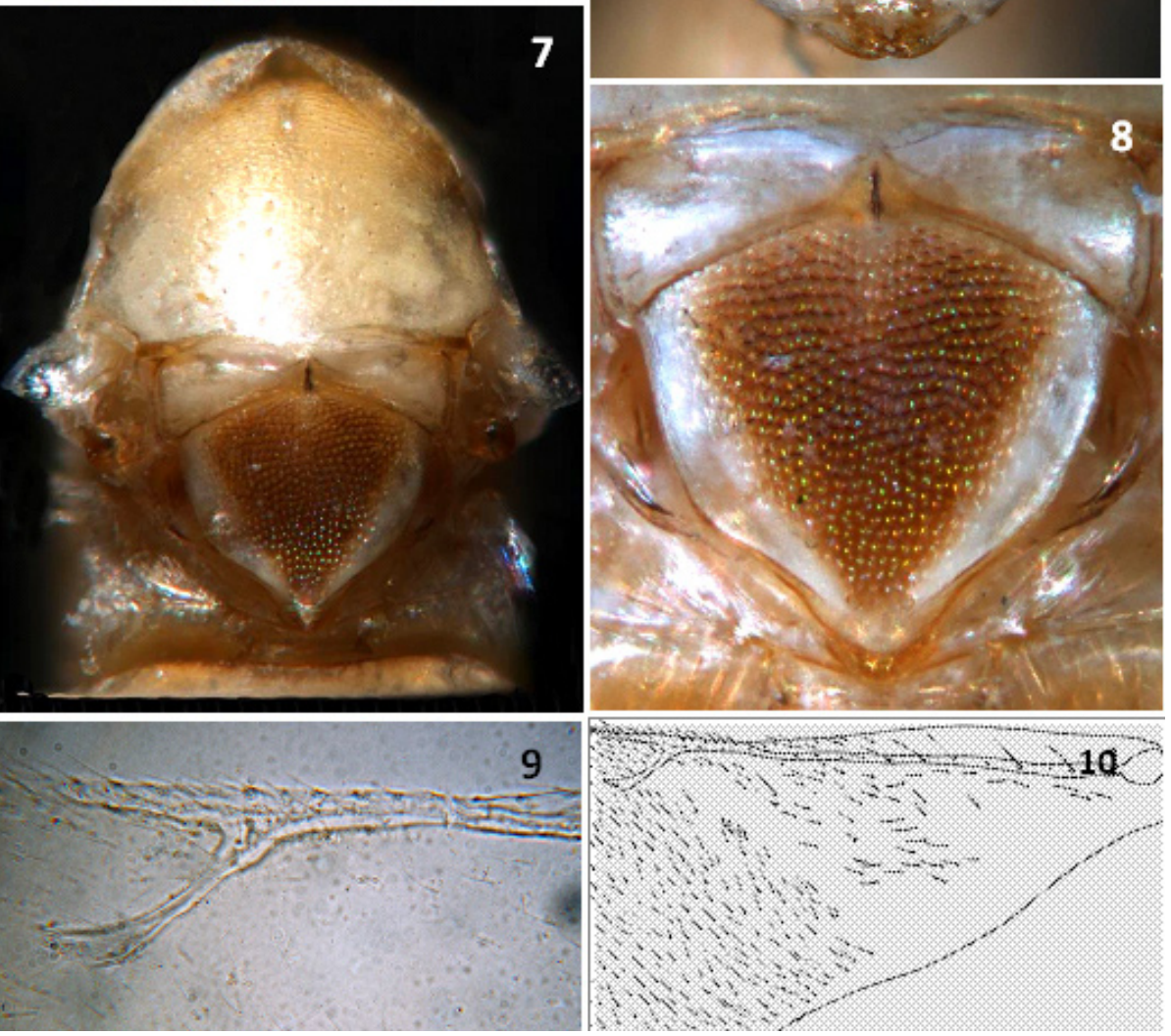

Images 5-10. Neastymachus punctatiscutellum Singh, sp. nov., female (holotype) 5 - head in dorsal view; 6 - head in frontal view; 7 - mesosoma; 8 - part of mesosoma showing sculpture on the scutellum; 9 - part of the fore wing showing venation and 10 basal part of the fore wing showing venation and setal pattern.

(c) Sudhir Singh

Structure: Head in dorsal view (Image 5) semicircular, anterior margin rounded, posterior margin concave; $1.8 \mathrm{x}$ as wide as long (587:317), $4.8 \mathrm{x}$ as wide as frontovertex width at level of median ocellus (587:120); ocelli in acute angle triangle; POL as long as, OCL $3.15 \mathrm{x}$ and OOL about $0.2 \mathrm{x}$ the diameter of middle ocellus (38:120:9:38); eye about $1.4 \mathrm{x}$ as long as wide (321:230). Head in frontal view (Image 6) rounded, slightly wider at eye and tapering towards genal area; $1.16 \mathrm{x}$ as wide as long (586:504); inner eye margins smoothly curved and diverging anteriorly from level of median ocellus; eye $1.7 \mathrm{x}$ as long as wide (370:216); toruli 1.6x as long as wide (78:48), half their length below the line joining lower ends of eyes; distance between toruli $1.34 \mathrm{x}$, distance between torulus and eye margin $1.53 \mathrm{x}$, torulo-mouth margin distance slightly shorter than torular length (105:120:72:78); scrobes narrow, moderately deep, not meeting dorsally, reaching halfway between torulus and median ocellus (168:340). Head in profile (Image 2) triangular, anterior margin smoothly curved, $2.5 \mathrm{x}$ as high as malar space length (504:201); eye $1.12 \mathrm{x}$ as long as wide (360:321). Antenna (Image 3) with scape flattened and expanded beneath, $2.3 \mathrm{x}$ as long as wide (264:114); pedicel long conical, $1.87 \mathrm{x}$ as long as wide (91:48); all funicle segments longer than wide; F1 slightly longer than pedicel, 2.96x as long as wide (95:32); F2 as long and as wide as F1, F3 2.27x (82:36), F4 1.65x (68:41), F5 1.36x (68:50), F6 1.23x (68:55); club 2.36x as long as wide (182:77). 
Mesosoma (Image 7): 0.9x head width (528:585); pronotum, visible part, narrow, about $9 \mathrm{x}$ as wide as long (432:48); mesoscutum convex from side to side, posterior margin at the middle curved and produced over the axillae separating them, $1.57 \mathrm{x}$ as wide as long (528:336); axillae rounded on sides, width of axillae $0.67 \mathrm{x}$ the thorax width (355:528); scutellum flat, conical apically, as long as wide (288); propodeum $11.2 \mathrm{x}$ as wide as long (538:48). Fore wing $2.5 \mathrm{x}$ as long as wide (1445:578); marginal vein (104) longer than postmarginal (68) as well as stigmal vein (91). Middle tibial spur slightly longer than basitarsus (211:192).

Metasoma (Image 1): Longer than mesosoma, $1.16 \mathrm{x}$ as long as wide (696:600), cercal plates situated slightly before middle of metasoma; hypopygium extending to two-thirds length along gaster; ovipositor length $0.73 x$ the mid tibia length (456:624), ovipositor sheath length $0.17 \mathrm{x}$ the ovipositor length $(77: 456)$.

Male: Unknown.

\section{Etymology}

Named after the distinct punctate reticulate sculpture of the scutellum.

\section{Distribution}

India: Western Ghats (Karnataka).

\section{Comments}

This is a distinct species and can be separated from other known species by shape (flat and apically v-shaped), colour (dark brown with lateral narrow white stripes) and sculpture (prominently deep punctuate reticulate) of the scutellum; flattened scape and the asetose scutellum. (See key to species.)

\section{REFERENCES}

Dahms, E.C. \& G. Gordh (1997). A review of the genera of Australian Encyrtidae (Hymenoptera: Chalcidoidea) described from Australia by A.A. Girault with a checklist of included species. Memoirs on Entomology, International 9: $v+518 p p$

Erwin, T.L (1982). Tropical forests: their richness in Coleoptera and other arthropod species. The Coleopterists Bulletin 36 (1): 74-75.

Erwin, T.L (1983). Beetles and other insects of tropical forest canopies at Manaus, Brazil, sampled by insecticidal fogging, pp. 59-75. In: Tropical Rain Forest: Ecology and
Management. Special Publication No. 2 of The British Ecological Society. Blackwell Scientific Publications. Boston, Massachusetts.

Girault, A.A. (1915). Australian Hymenoptera ChalcidoideaVII. The family Encyrtidae with descriptions of new genera and species. Memoirs of the Queensland Museum 4: $1-184$.

Hayat, M. (1999). Taxonomic notes on Indian Encyrtidae (Hymenoptera: Chalcidoidea)-V. Oriental Insects 33: 349-407

Hayat, M. (2006). Indian Encyrtidae (Hymenoptera: Chalcidoidea). Published by M. Hayat, Department of Zoology, Aligarh Muslim University, India, 496pp.

Mitchell, A.W. (1986). The Enchanted Canopy. Macmillan Publishing Company, New York, 288pp.

Nikol'skaya, M. (1952). Chalcids of The Fauna of The USSR (Chalcidoidea). Opredeliteli po Faune SSSR. No. 44: Zoologicheskim Institutom Akademii Nauk SSSR, Moscow and Leningrad, 575pp

Noyes, J.S. (2010). Encyrtidae of Costa Rica (Hymenoptera: Chalcidoidea) -3. Memoirs of the American Entomological Institute 84: 848pp.

Noyes, J.S. \& Hayat, M. (1984). A review of the genera of IndoPacific Encyrtidae (Hymenoptera: Chalcidoidea). Bulletin of the British Museum (Natural History) (Entomology) 48: 131-395.

Noyes, J.S., J.B. Woolley \& G. Zolnerowich (1997). Family Encyrtidae. Chapter 8, pp. 170-320. In Gibson, G.A.P., Huber, J.T. \& Woolley, J.B. (eds.). Annotated Keys to the Genera of Nearctic Chalcidoidea (Hymenoptera). National Research Council Canada, NRC Research Press, Ottawa, 794pp.

Prinsloo, G.L. (1996). Neastymachus dispar sp. n. (Hymenoptera: Encyrtidae), a parasitoid of Cribrolecanium andersoni (Newstead) (Hemiptera: Coccidae) on citrus in southern Africa. African Plant Protection 2(2): 117-120.

Shafee, S.A., S.M. Alam \& M.M. Agarwal (1975). Taxonomic survey of encyrtid parasites (Hymenoptera: Encyrtidae) in India. Aligarh Muslim University Publications (Zoological Series) on Indian Insect Types 10: iii+1-125pp.

Singh, S. \& M.M. Agarwal (1993). Taxonomic studies on Indian encyrtid parasites (Hymenoptera: Encyrtidae) from north-eastern region. Aligarh Muslim University Zoological Publication on Indian Insect Types 14: 180pp

Singh, S., M.M. Agarwal \& M.C. Basha (1991). Descriptions of three new species of Neastymachus (Hymenoptera: Encyrtidae) from north-eastern India. Oriental Insects 25: 221-230.

Singh, S. \& Y.B. Srinivasa (2010). Description of a new species of the genus Eutrichosomella Girault (Hymenoptera: Chalcidoidea: Aphelinidae) from the Western Ghats, India. Annals of Entomology 28(2): 1-5.

Smythe, N. (1982). Seasonal abundance of night flying insects in a neo-tropical forest, pp.309-318. In: The Ecology of A Tropical Forest: Seasonal Rhythms and Long-term Changes. Smithsonian Institute Press. Washington, DC. 
Key to Afrotropical, Australian and Oriental species of Neastymachus (females) (partly based on Singh \& Agarwal 1993, and Hayat 2006)

1 Fore wing basal triangle with a large bare area; metasoma usually subequal in length to mesosoma, apically rounded, and with cercal plates situated in about middle; occipital margins sharp (except in angustifrons); anterior face of pronotum usually with a central dark brown spot ............................................. 2 Fore wing basal triangle setose to base, with at most a small bare area; metasoma at least slightly longer than mesosoma, pointed apically, and with cercal plates situated in about basal third; occipital margins narrowly rounded, not sharp; anterior face of pronotum with a broad transverse dark brown stripe ..................... 7

2 Body strikingly bicolourous; head entirely black, mesosoma and gaster blackish-brown to almost black except distal half of mesoscutum, entire prepectus and scutellum brownish-yellow; antenna sordid white to pale brown with club largely brown. (South Africa; Swaziland) ............................................................dispar Prinsloo Body mostly pale yellow to orange, only certain small areas on genal margins, scape, club, postocciput,

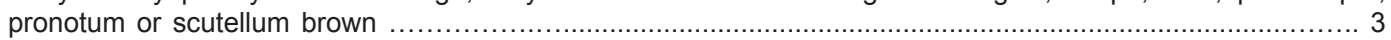

3 Frontovertex at level of median ocellus about $0.2 x$ of head width; ocellar triangle with apical angle acute; antennal club may or may not be brown ................................................................................... 4 Frontovertex at level of median ocellus broader, at least about $0.33 x$ of head width; ocellar triangle with apical

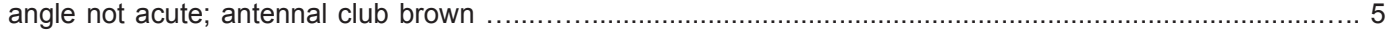

4 Scape cylindrical, about 5.0x as long as wide; F1 equal to pedicel in length; antennal club dark brown; body completely yellow, except a brown patch at the centre of anterior face of the pronotum (India); scutellum with black setae ............................................................................ angustifrons (Shafee, Alam \& Agarwal)

- Scape expanded, about $2.3 x$ as long as wide; F1 distinctly longer than pedicel; antennal club white; body completely pale except scutellum brown with lateral narrow white stripes; scutellum without setae (India) ....... punctatiscutellum Singh, sp. nov.

5 Antennal scape short, and slightly flattened, not more than 3.0x as long as wide; fore wing proximal to linea calva with numerous setae (more than 70); ovipositor sheath not more than one-fifth length of second valvifer; malar area concolourous with face

- Antennal scape relatively long, at least $4.0 x$ as long as broad; fore wing proximal to linea calva with fewer setae (less than 40 ); ovipositor sheath $0.28 x$ the length of second valvifer; lower malar area dark brown (India) .. cerococci (Shafee, Alam \& Agarwal)

6. Scape yellowish, 3.0x as long as wide; F1 longer than wide, rest of funicle segments, subequal, quadrate to wider than long; ovipositor sheath $1.5 \mathrm{x}$ as long as wide and $0.16 \mathrm{x}$ second valvifer length; occiput without a brown spot (India) ............................................................................. burksi (Shafee, Alam \& Agarwal) Scape dark brown, $2.5 x$ as long as wide; all funicle segments longer than wide; ovipositor sheath about $3 x$ as long as wide and 0.19x second valvifer length; occiput with a brown spot (India)

.latiscapus Singh, Agarwal \& Basha

7. Funicle with F1 and F2 each at least twice as long as wide, remaining segments shorter but all longer than wide; body yellow to yellowish-brown ............................................................................................... 8 All the funicle segments at least about twice as long as wide; body testaceous. (Malar space brownish, frontovertex light brown, occiput with a dark brown spot on the occiput behind the eyes; pronotum with dark brown anterior to collar and a spot on each side; distal two-thirds of scutellum and sides of propodeum light brown, gaster dark brown) (India) .......................................................................... delhiensis (Subba Rao)

8. Frontovertex at level of median ocellus $0.33 x$ head width; F1 slightly longer than pedicel; ovipositor slightly exserted, about one-tenth of gaster length; body with head and mesonotum light brownish-yellow, gaster brown, VII-tergum lighter; two dark brown spots on either side of occiput behind the eyes; pronotum with broad transverse dark brown stripe on the anterior face of pronotum which extends dorsally and appear as spots on collar on either side. (Scutellum distinctly deep reticulate) (India) ................. axillaris Singh, Agarwal \& Basha Frontovertex at level of median ocellus $0.29 x$ of head width; $F 1$ shorter than pedicel; ovipositor exserted by about a-fifth (0.19x) of gaster length; body yellow brown; a narrow black patch transversely across occiput behind eyes which aligns with a broad transverse black stripe on anterior face of pronotum (Australia)

auraticorpus Girault

Srinivasa Y.B., A. Kumar \& K.D. Prathapan (2004). Canopy arthropods of Vateria indica L. and Dipterocarpus indicus Bedd. in the rainforests of Western Ghats, South India, Current Science 86(10): 1420-1426.

Stork, N.E. (1991). The composition of arthropod fauna of Bornean lowland rain forest trees. Journal of Tropical Ecology 7: 161-180.

Subba Rao, B.R. (1957). Some new species of Indian Hymenoptera. Proceedings of the Indian Academy of Sciences (B) 46: 376-390.

Sutton, S.L, C.P.J. Ash \& A. Grundy (1983). The vertical distribution of flying insects in lowland rainforests of Panama, Papua New Guinea, and Brunei. Zoology Journal of Linnaean Society 78: 287-297.

Tachikawa, T. (1970). Notes on some Japanese species of Encyrtidae (Hymenoptera: Chalcidoidea). Transactions of the Shikoku Entomological Society 10: 100-106.

Trjapitzin, V.A. (1962). Encyrtidae (Hymenoptera) - parasites of Nipponaclerda turanica (Arch.) (Homoptera:Aclerdidae) in Nogai steppe. Zoologicheskiy Zhurnal 41(4): 560-570. 